\title{
Man is Consubstantial with God Moral Reflections on Humanism
}

\author{
Haijie Liu \\ Chifeng University College of Elementary Education, Chifeng, 024000, China
}

\begin{abstract}
Early Renaissance man regained the independence of individual personality, but by the fear of God into the evolution away from God, from the backwash toward the loss. Late Renaissance reflection and adjustments is comforting one, rational constraints original desire, divinity give directions to humanity, which is the most profound meaning of humanism. For human freedom and liberation, post-humanism made a valuable exploration, by absorbing humanistic ingredients of the ancient Greek - Roman and Hebrew - Christian culture, tried to avoid walking single dimension of cultural evolution orientation.
\end{abstract}

\section{Keywords- Humanism; Humanity; Divinity}

"People cannot give up himself. As possibility of freedom, you must become either truly free or become a free reverse."[1]

The Renaissance era is called the "Discovery", mankind finally freed from the harsh medieval theology and the middle ages of God's divinity. They saw their great noble, rational human nature to be assertive. People sleeping stand up to pursue the freedom, enjoy the rights of human being, filled with passion of life, full of vigorous vitality. Of course, the "Discovery" can also be seen as a cultural generation process, it continues to explore the level of humanity and the connotation of human being. In the meantime, individual generic definition of human has been established. The human race touch himself times and times in cultural selection. They're also struggling on the road to the liberation of development.

\section{BetweEn GAINS AND LOSSES - LiBERATION AND CONFUSION}

Renaissance people-oriented value system of thought including individualism, egoism values and behavioral norms route, to promote the development, technological advances of civilization and human substance to improve the social and economic life of the objective, these are people from the barbaric necessary path toward civilization, there are also people of the value of the basic conditions to be achieved. In addition, it is unreasonable to get rid of the control of their own religion and culture, the proposed concept of emotional happiness doctrine, the process of human freedom and liberation has taken an important step for the return of people to make a full and true history of efforts. Economic development and social prosperity, human emancipation became identified specific human existence, the state of human existence as a side evaluation scale, while Renaissance humanism can obtain affirmative evaluation, with the provisions of goodness.

Utilitarian moral principle, for example, they can be said to be based on the previous route of human behavior. This ethics course has merit, and happiness of human beings has been selected as the final value basis, the progress of the liberation of mankind has always been our unwavering goal. In addition, it is "reasonable self-interest" excludes the absolute position of absolute selflessness and self-interest of these two extreme values, so that self-interest by individual rationality and regulation of public reason, in theory, have the correct guidance of public acts of personal or social constraints selection effect.

In early humanism, the ancient Greek Dionysus took soul and went back to the pursuit of happiness in earthly, people live life to show vitality. However, it is widely held at the same time sensual doctrine concept of happiness and pursuit of personal interests has been upgraded to the code of conduct. Although this would have beneficial positive effects, it also caused a lack of moral responsibility rational social order to bring chaos.

But we should also see some limitations of the humanistic ideas of them. For example, advocate the use of moral influence to tame the wicked, so as to achieve the purpose of good over evil, which can not only be a moral ideal, but also lack of realistic operational. Not alone eliminate evil from good and for evil, wicked moral radiation can be achieved, but also on the formation of social law system constraints and their perpetrators correct moral values. Talk about sound social imperative, Aristotle would have been made known to the good and to do good, good depends on two aspects of joint action. People only know what is good, and do good voluntarily, when the behavior it has a moral value, and can effectively eliminate the evil breed. In other words, the two premises of voluntary rational consciousness and the will of a moral behavior can be established are indispensable. For evil to reduce and disappear, which is needed to achieve the standards of humanity.

Utilitarian size as the only measure also belittle the human virtues of the spirit, people tend to ignore the rare nature, utilitarian look for the provision of a single dimension of human nature. In addition to the pursuit of human emotional desire utilitarian, there is more lofty moral rational pursuit. It essentially abolished the distinction between human and animal basis. In addition, utilitarian 
oriented philosophy and behavior will not be able to avoid the spread of instrumental rationality such as the benefit of unscrupulous and other non-moral or immoral problems.

\section{COMPLETE HuMAN - INTEgRATION BETWEEN THE Dimensions AND SAVING BETwEen ETHICAL MutuaL}

Human should be unified diversity and multidimensional presence. Thus, the human scale should be harmony unity. However, the Renaissance Human clashed between multiple dimensions, not only gave birth to the unreasonable phenomenon, namely the reality of people on earth who unilaterally onrush, the loss of social and moral attributes the decline became a desire to meet the cost. And the emergence of abnormal development of human society, which is due to human scale - uncoordinated body and soul, between the original desire and reason. From this perspective, the natural desire that makes the original human, but due to human scale internal discord, thus became evil. The roots, this is because over development of some human multiple prescriptive not conducive to human progress. After achieve a person's integrity, the reasonable original desire to recovered because without restraint, since essentially unlimited expansion for the digestion of this integrity.

In this era of major historical turning point during the Renaissance, the social mode of production, lifestyle and human existence of specific changes have occurred, and both the moral values of the previous generation to the next backwash system specific scenes, often more susceptible to moral standards contradictions and historical scale, productivity progress, social progress and moral values situations of conflict. In this sense, human understanding of the late Renaissance to the early return to the rational way biased original desire for cultural and moral judgment system type generated by actively corrected, the realization of human and divine nature, and God's reconciling again, so evaluation of weak moral and ethical dimensions allow located efficiency scale, economies of scale, utility-scale unreasonable conditions have improved, the evolution of human civilization in the process of beneficial adjustments.

Adhere to the unity of moral and historical dimensions of the scale, do not give up the moral evaluation and historical evaluation of any kind, are standard objective judgment that any period of human history we should be held. It is revealed to us in the course of development of human society, the return of the full human scale, not to give up the value of the relationship between the vitality of practical reality, there are also consciously seek shared an objective universal moral and spiritual norms, and in changing accurate understanding of the living world in their specific prescriptive. This spirit of shared basic values of human civilization thousands of years of evolution in the formation, is indelible spiritual strength, but also to guide people and the community to overcome evil, tend to kind of eternal wealth..

\section{PeOPle Of God InTO OnE}

Overemphasis on religious theology and divinity of God will cause damage and distortion for human. In the early Renaissance man to regain the independence of individual personality, wishes to recover reasonable lost. This meaning is almost identical to let the blind see again, but it seems that this is extremely indignant psychological mechanisms and too rebellious Ji Gong strong desire to cause problems facing the opposite extreme direction. In the "natural human desires reasonable" deafening cries, the people's pursuit of selfish desires from the field of behavioral ideas showed widespread blindness and extreme, leading to imbalances deviation values and principles on the conduct of people fell into the desire abyss. Thus, individualism evolved into extreme individualism, personal happiness and social wellbeing unified mind caused a huge fissure between the individual and society, so people had to endure the pain created by his own culture.

In fact, this is not unexpected in the minds of some thinkers and writers. They are Renaissance people-oriented value systems and behavior and have been doing already deep reflection. The latter reflects the rational spirit of humanism Christian culture, which they treat social maladies recipe. Natural impulse of love desires moral constraints plus the love of God will not let evil desires erosion sensible person. This not only achieves a reasonable wish of ancient Greek style, but also practices the ultimate value of the Hebrew-style pursuit. Human flesh material, but also the soul of the spirit, which is different from the ancient Greek style flesh carnival, but also from the Christian doctrine of spiritualism; person is a reality, but also implicit super reality trend. People should use their own humanity in divinity (love, generosity, justice) good deeds increasingly good and build a better world in the world. For the original core of the Dionysian spirit, reason is the core spirit of the day of God, both take care of each other. Obey the divine humanity coaching, is the late Renaissance of human understanding, is the most profound meaning of humanism. This undoubtedly is a mature than over the previous humanist and progressive. It excludes the pre-humanist inheritance of the traditional emphasis on secular people crazy vulgar ingredient original desire, but also denied the external restraint system of Christian theology and human alienation of God, but retained the tradition of religious people in this broad and deep God of love. For human survival and development, freedom and liberation, post-humanism made a valuable exploration. It incorporates the humanities component of the ancient Greek - Roman and Hebrew - Christian culture, try to avoid walking single dimension of cultural evolution orientation.

The same is true understanding of freedom. People are keen to grab the subject of freedom where the early Renaissance lost in alienation opposites - God and Christ theology institutions and get rid of the slavery that illusion of individual spirit and freedom of movement from the other side of the world. But overkill, people falled from the theology of purgatory again into the main body of 
purgatory, become secular world wishes to cross-flow of small dust and drifting boat. When people think that freedom is meeting flesh, materialism and other rights of individuals, in the era of climate impact, the eternal law of rational spirit declining gradually been discarded forgotten. In the hustle and bustle of people in pursuit of freedom truly free themselves deprived and exhausted, man succumbed to the flesh and paid dearly, became a servant of desire. Therefore, it is particularly timely, but also important that post-humanism called for social responsibility, justice, love and other moral spirit, make noble feelings and emotions secular together to maintain independence and freedom of human.

\section{CONCLUSION}

"Man is a rational man is free, man is the only possible moral." [2] is the only possible and then overthrow the establishment of moral ethics, and continue debugging respect ethical and moral. Converting to heaven, soul, afterlife constitutes religious moral, spiritual salvation built a cage for live life and forced the Renaissance onwards and crushed it, but too much momentum due to the outbreak of the noble divinity also be destroyed. Human again seem barbaric - new self as barbaric. Desires of the flesh also got the egitimacy beyond the scope of rational outside the normal stretching. In this case, the Christian nature of the rational pursuit of human glow dazzling brilliance. In the process of earthly individual moral and groups ethical constantly evolving, religious morality is still nutritious spiritual heritage.

\section{REFERENCES}

[1] Karl Jaspeers. Mental state of the times[M]. Translated by Wang Defeng, Shanghai: Shanghai Translation Publishing House, 1997, pp.155

[2] Reinhold. Niebuhr. Moral and immoral society[M]. Translated by Peng Xueyun, Guizhou: Guizhou People's Publishing House, 1998, pp.201

[3] Jacob Burckhardt. The Italian Renaissance culture[M]. Translated by He Xin, Beijing: Commercial Press, 1979.

[4] Qi Liang. Introduction to Western culture[M]. Guangzhou: Flower City Publishing House, 2000, PP.368

[5] Allen • Bullock. Western humanist tradition[M]. Translated by Dong Leshan, life • Reading • Joint Publishing, 1997. 